\title{
Can we find out if COVID-19 causes diabetes?
}

\author{
PHILIP HOME
}

Key words: diabetes, diagnosis, COVID-19

Diabetes and serious COVID-19 infection have presented a series of challenges, as many readers and the people they care for will know to their cost. The most important of these has been the markedly increased risk for people with diabetes of hospitalisation, diverse inflammatory complications following the acute infection and death. ${ }^{1}$ This in turn has raised clinical questions such as the means and level of glucose control for management of inpatients, but also pathogenetic questions around why people with both main types of diabetes are at heightened risk.

The debate in the literature around glucose control after admission has focused on whether poor control is prognostic for poor outcome. ${ }^{2}$ Part of the problem in understanding this is reverse causation - does poor glucose control increase the risk of poor outcomes or does a higher inflammatory state from more severe infection per se cause a higher degree of insulin resistance and thus raise plasma glucose? Or indeed both? A difficulty here has been publications that were opaque on ascertainment of diabetes - were the 'diabetes' populations studied defined by prior diabetes, excluding those without prior diagnosis, and for those in whom diabetes was not previously recognised, were they undiagnosed diabetes at the point of admission or people manifesting the hyperglycaemia of metabolic stress? A further difficulty is that measurement of $\mathrm{HbA}_{1 \mathrm{c}}$ at admission has not usually been included in lists of initial investigations, meaning that for those without a formal prior diagnosis, the issue can never be resolved.

But the occurrence of diabetic ketoacidosis (DKA) in people who were not known to have diabetes prior to admission (in anyone with prior diabetes later development of DKA as an inpatient is simply negligent clinical care) has raised the question as to whether COVID-19 infection can itself cause diabetes, either directly through viral damage to islet B-cells or through the long-known sensitivity of these cells to cytokine-induced damage. ${ }^{3}$ The other possibility is simply precipitation of clinically

Translational and Clinical Research Institute, Newcastle University, UK

Address for correspondence: Professor Philip D Home Translational and Clinical Research Institute, The Medical School, Framlington Place, Newcastle upon Tyne NE2 4HH, UK

Tel: +44 (0)19 12087182

E-mail: philip.home@newcastle.ac.uk

Br J Diabetes 2021;21:1-2

https://doi.org/10.15277/bjd.2021.303

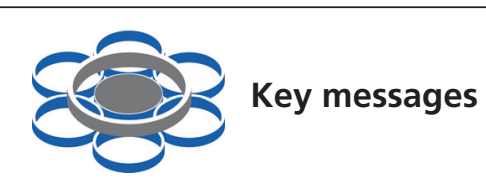

- It is not unusual for new hyperglycaemia to be found in people admitted for management of COVID-19

- This raises questions of whether this is stress hyperglycaema, previously unrecognised diabetes, newly precipitated diabetes, or newly caused diabetes

- A new initiative to register such cases has been announced and is very welcome, but will have difficulties resolving the issues

obvious diabetes in those in whom it would anyway have become manifest in the months and years that follow. These arguments go back 40 years or more to long-held theories of the aetiology of usual type 1 diabetes, although the viral candidates suggested seem never to have included coronaviruses. Of course, type 1 diabetes has now long been understood to be a disease of very gradual (years or decades) aetiology, although again any acute illness - be it infection or metabolic trauma can then push an individual into symptomatic hyperglycaemia and ketoacidosis. So much is confirmed by the observation that people with type 2 diabetes can present in DKA, or develop DKA with metabolic stress.

The announcement that Rubino and colleagues have secured a project to investigate this is then welcome. ${ }^{4}$ But with caution. Case identification and reporting after COVID-19 admission may fall foul of the same problems of lack of defining information noted above. Without islet cell antibodies or $\mathrm{HbA}_{1 \mathrm{c}}$ prior to admission (or on admission), it will never be possible to be sure when the pathogenetic process started, or how far it had progressed at the time of first contracting COVID-19. The group is no doubt aware of the issues, and the initiative worth supporting, but in the end the question may only be resolved for the few in whom serendipitous storage of serum had occurred in prior years. It has been recognised since the 1980s that islet B-cells might be unusually sensitive to cytokine damage, ${ }^{5}$ but rather like any demonstration of presence of viral RNA or antigen in the islets of deceased people (of whom, sadly, there will be many), any association with circulating cytokines cannot fulfil Koch's postulates.

Meanwhile possibly more important questions remain unsolved. While there have been many attempts, largely point- 
less, to identify risk of poor outcome at the time of admission, attempts to define within the ambulatory diabetes population who is at increased risk for serious outcome remain worthy but incomplete. ${ }^{6}$ We have excellent datasets including measures such as ALT and (micro)albuminuria which have a strong chance of being highly predictive, and it beholds those with these to address that question.

\section{Conflict of interest None \\ Funding None}

\section{References}

1. Barron E, Bakhai C, Kar P, et al. Associations of type 1 and type 2 diabetes with COVID-19-related mortality in England: a whole-population study. Lancet Diabetes Endocrinol 2020;8:813-22. https://doi.org/ 10.1016/S2213-8587(20)30272-2

2. Bloomgarden Z. Does glycemic control affect outcome of COVID-19? J Diabetes 2020;12:868-9. https://doi.org/10.1111/1753-0407.13116

3. Entwistle A, Edwards AE, Benjamin A, Gelding SV, Gunganah K. Diabetic ketoacidosis (DKA) admissions during and before the COVID-19 pandemic (abstract A10.) Diabet Med 2021;38(Suppl 1):5

4. Rubino F, Amiel SA, Zimmet $\mathrm{P}$, et al. New-onset diabetes in COVID-19. N Engl J Med 2020;383:789-90. https://doi.org/10.1056/NEJMc2018688

5. Mandrup-Poulsen T, Helqvist S, Wogensen LD, et al. Cytokines and free radicals as effector molecules in the destruction of pancreatic beta cells. Curr Top Microbiol Immunol 1990;164:169-93. https://doi.org/10.1007/ 978-3-642-75741-9 9

6. Holman N, Knighton P, Kar P, et al. Risk factors for COVID-19-related mortality in people with type 1 and type 2 diabetes in England: a population-based cohort study. Lancet Diabetes Endocrinol 2020;8:823-33. https://doi.org/10.1016/S2213-8587(20)30271-0

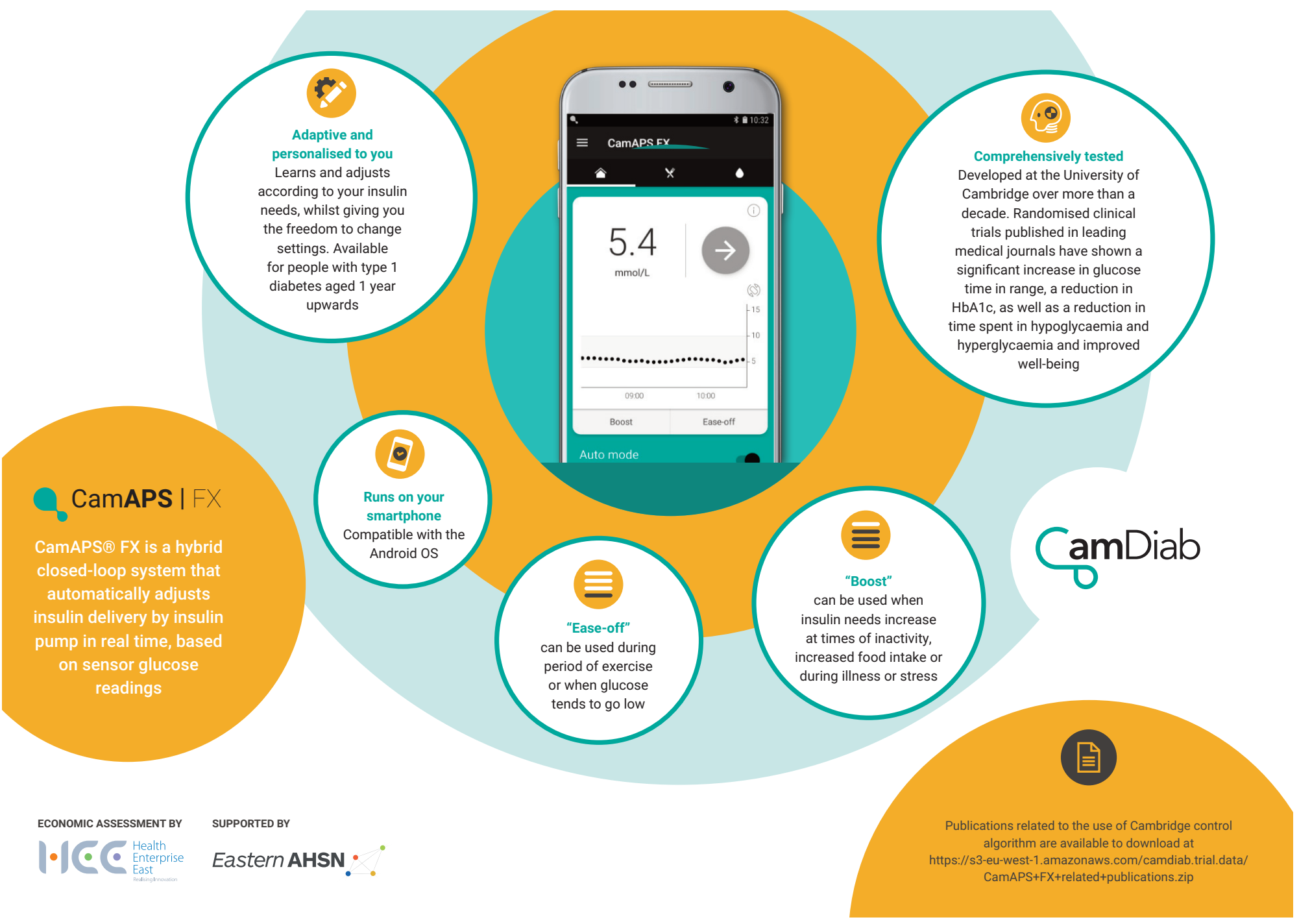

